ENSAYO

\title{
LECTORES LEÍDOS, ESCRITORES CONTADOS
}

\author{
Jorge Edwards
}

Jorge Edwards confiesa en estas páginas que sus relecturas recientes del Quijote le llevan a concluir que se trata de un texto mucho más autobiográfico de lo que había imaginado. Todo indicaría que en la experiencia vital de Cervantes hubo un Quijote, quizá muchos, como también hubo, y más de una vez, un Sancho Panza. Así, en el Quijote se encontraría presente la opinión de Cervantes sobre la literatura y la lectura, donde la sugerencia de que la vocación literaria tiene en su origen una locura de lector, no está lejos, como en los lectoresescritores de Jorge Luis Borges y de Joachim Machado de Assis.

Jorge Edwards (1931). Escritor y ensayista chileno, nacido en Santiago. Miembro de la Academia Chilena de la Lengua, en 1994 recibió el Premio Nacional de Literatura y en 1999 el Premio Cervantes de Literatura, entre otros muchos reconocimientos y galardones. Se desempeñó como diplomático en París junto a Pablo Neruda (lo que narra en sus memorias Adiós, poeta, 1990), y en la Cuba de Fidel Castro (también en sus memorias Persona non grata, 1973). Autor de una vasta obra que incluye cuentos, El patio (1952), Gente de la ciudad (1962), Las máscaras (1967), Temas y variaciones (1969) y Fantasmas de carne y hueso (1992), y novelas como El peso de la noche (1965), El convidado de piedra (1978), El museo de cera (1981), La mujer imaginaria (1985), El anfitrión (1988), El origen del mundo (1996), El sueño de la historia y El inútil de la familia (2004).

Estudios Públicos, 100 (primavera 2005). 
$\mathrm{L}$

a tendencia que conduce a exaltar al personaje de ficción y a menospreciar al escritor de carne hueso, como si la creación del personaje fuera un hecho excepcional en la vida de su autor, un producto del azar, no una consecuencia de la biografía literaria, es antigua y persistente en la crítica del Quijote. Se diría que el desprecio por Miguel de Cervantes de muchos de sus contemporáneos, iniciado con singular mezquindad y ceguera por Lope de Vega, ha continuado en una u otra forma hasta años muy recientes. Todos piensan que la invención de don Quijote de la Mancha y de su escudero Sancho Panza es una ocurrencia genial, un momento único en la historia de la literatura, pero muchos ven el invento como un acto aislado, producido por una inspiración súbita y casi ajena a su autor. El prestigio del autor, del Miguel de Cervantes de carne y hueso, en otras palabras, es curiosamente inferior al prestigio de su gran libro. No sé si esto es una proyección de la famosa envidia hispánica. Hace poco, en Madrid, en pleno año del cuarto centenario del Quijote y entre gente de cultura, escuché decir, con verdadero asombro de mi parte, que Cervantes había sido un "cobardica" y que no había tenido escrúpulos en vivir de sus hermanas mal afamadas. En otras palabras, mis interlocutores afirmaban que Cervantes había sido cobarde y medio alcahuete. Ni más ni menos. Eran los desprecios de Lope de Vega resucitados cuatro siglos más tarde.

En su Vida de don Quijote y Sancho, publicada por primera vez en 1905, coincidiendo, como sostiene su autor, "por acaso, no de propósito", con la celebración del centenario anterior, Miguel de Unamuno hace la apología exaltada del Caballero de la Triste Figura, que llega a adquirir en su interpretación una aureola de santo laico, y recluye a Cervantes en una especie de limbo grisáceo. Desde el primer capítulo, el ensayo unamuniano es una apasionada invitación a buscar y a liberar, en una cruzada moderna, ilógica, peligrosamente precursora de otras cruzadas que vinieron más tarde en su país, el sepulcro de don Quijote. Por lo demás, en sus novelas ensayísticas, que él solía llamar "nivolas" para diferenciarlas del género tradicional, así como André Gide, en los mismos años, elaboraba una diferencia entre sus "récits" y sus "soties", Unamuno insiste en el tema de la rebelión de los personajes, que así desafían la omnisciencia del novelista todopoderoso, el dios de la novela. En su locura, Don Quijote, San Quijote, tiene también por ahí algún rasgo de arrogancia luciferina. No es un personaje en busca de autor sino en lucha con su autor, que aspira a liberarse de su sofocante abrazo y a caminar por el mundo con autonomía, sin depender para nada de su pluma. 
Confieso que en mis lecturas de adolescente, iniciadas, para poner las cartas sobre la mesa, cuando todavía no salía de las aulas del Colegio de San Ignacio, la influencia de Miguel de Unamuno, el escritor español que me apasionó en esos años por encima de todos los demás, fue determinante. Debo reconocer, entonces, que mi primer Quijote fue el suyo, el de su famosa Vida de 1905. Ahora, a más de medio siglo de distancia y después de muchas relecturas, comprendo que era un Quijote con aires de Federico Nietzsche y de Sören Kierkegaard, con fuertes elementos de voluntarismo, de algo que el propio Unamuno llamaba cristianismo agónico. Así se comprende que este manchego por definición, Don Quijote, o Alonso Quijano el Bueno, si prefieren ustedes, tuviera una curiosa vertiente vasca, más notoria para mí en los tiempos que corren y después de haber pasado en España largas temporadas: era un Nietzsche, digamos, modificado por la perspectiva de Ignacio de Loyola, otro santo, junto a Don Quijote, que también provenía de la milicia y que estaba igualmente emparentado con el mundo caballeresco medieval.

Mi impresión actual de relectura, y lo digo sin pretensiones críticas o teóricas, como una simple propuesta, o como una impresión de lectura, es exactamente inversa a la de Unamuno y sus numerosos seguidores. Ellos, quijotistas declarados, no toman demasiado en serio a Miguel de Cervantes. En alguna medida, esa concentración mistificadora, buscadora de símbolos y de toda clase de mensajes extraliterarios en la figura del caballero, les impide comprender bien la relación genial, iluminadora, única, entre el escudero y su amo, relación dialógica, para emplear un término de Mikhail Bakhtin, y que mantiene vivo el dinamismo de la novela hasta el último capítulo. Mi conclusión, pues, la de mis lecturas recientes, coloca en el centro, en el eje del texto, a su propio creador. En otras palabras, hoy tiendo a pensar que el Quijote es obra mucho más autobiográfica de lo que me imaginaba hasta aquí. Porque el Quijote y Sancho, el caballero y su escudero, son antípodas, figuras contrastadas, posibilidades opuestas y extremas, pero también facetas, proyecciones parciales del espíritu cervantino. Todo me indica, hoy, que en la experiencia vital de Cervantes hubo un Quijote, quizá muchos Quijotes, y hubo también, y más de una vez, un Sancho Panza. El Cervantes quijotesco, por ejemplo, aparece en la mañana de la batalla de Lepanto, o en sus diversos intentos de huida del cautiverio de Argel, intentos en los que arriesgó la vida para escapar de la esclavitud, así como el Cervantes sanchopancesco es el que conseguía sobrevivir en el mismo Argel, en Valladolid, en Andalucía, en Madrid, en todas partes. En su 
reciente recolección de ensayos cervantinos ${ }^{1}$, Martín De Riquer cita las palabras del alférez Gabriel de Castañeda en una información formal de 1578, es decir, de la época en que el escritor se encontraba cautivo. La información fue realizada probablemente para ayudar a recaudar los fondos necesarios para el rescate. Pues bien, el alférez Castañeda, testigo directo de los hechos, cuenta que Cervantes estaba enfermo y con fiebre el día de la batalla de Lepanto y que su capitán le pidió que no pelease y se retirase bajo la cubierta. "Y entonces vio este testigo", dice la declaración, "que el dicho Miguel de Cervantes respondió al dicho capitán . . . muy enojado ... más vale pelear en servicio de Dios y de su Majestad, y morir por ellos, que bajarme so cubierta". Agrega Castañeda que Cervantes le pidió a su capitán que "le pusiese en parte y lugar que fuese más peligrosa y que allí estaría o moriría peleando, como dicho tenía". En una circunstancia así, en víspera de alguna gran batalla contra infieles, el Caballero de la Triste Figura no habría respondido de otra manera.

Habría que estudiar al mismo tiempo la identificación de Cervantes con la sabiduría realista, tradicional, de origen netamente popular, de Sancho Panza. El que nos da las mejores pistas en esta materia todavía es Américo Castro en su estudio clásico, aparecido por primera vez en España en 1925, El pensamiento de Cervantes, ensayo cuyo título equivale ya a un desmentido. En el capítulo IV, en los apartados dedicados a los refranes y a la lengua vulgar, Américo Castro nos muestra que la visión renacentista de la naturaleza y de lo natural en los seres humanos, asimilada a fondo por Cervantes, lo hacía sentirse muy cerca de la sabiduría y hasta del lenguaje, con su inagotable riqueza de dichos y proverbios, del escudero, a pesar de su evidente fascinación ante la espiritualidad enloquecida, desarraigada, desequilibrada, además de libresca, del caballero. Se podría aventurar, entonces, que Cervantes, gran narrador de peripecias, como lo demuestra a cada rato en las novelas ejemplares, en el Persiles, en largas páginas del Quijote, recreador eximio de formas narrativas derivadas de la Antigüedad y de la Edad Media, hizo a la vez una innovadora literatura del yo, como la hizo a conciencia su casi contemporáneo Michel de Montaigne. "Ainsi, lecteur, je suis moi-mêmes la matière de mon livre", escribió Montaigne en la advertencia al lector de sus ensayos reunidos. Mi nueva lectura me induce a creer que Cervantes pudo declarar lo mismo, con la salvedad de que el escenario que proyectaba su imaginación de novelista era más rico que el de Montaigne, más exterior a él mismo, a pesar de todo, y más variado.

${ }^{1}$ Martín de Riquer: Para Leer a Cervantes (Acantilado, Barcelona, 2003), p. 44. 
Comprendo que estas propuestas, estas impresiones de lectura y relectura, nos pueden llevar a círculos demasiado enrarecidos, a terrenos extraños y un tanto movedizos. He sostenido un poco antes que el Quijote, en mi lectura de años recientes, me parece un texto mucho más autobiográfico de lo que me había imaginado antes. Pues bien, uno de los recursos clásicos de los narradores modernos para retratarse a sí mismos, para hacer a través de diversos subterfugios y disfraces una literatura del yo, consiste en colocar lectores, escritores y escribidores de la especie más diversa en el interior de sus textos narrativos. El cuento y la novela modernos, y hablo aquí de modernidad en un sentido amplio, están llenos de historias de lectores y de escritores que a veces retratan en forma directa al autor real y que más a menudo todavía lo esconden o lo retratan en forma parcial, deformada. Desde luego, el hidalgo de la Mancha, pronto ungido caballero por decisión propia, es un lector empedernido, un fanático de la lectura, a quien conocemos en el momento mismo en que ha dejado de leer para transformarse en personaje de sus lecturas. Es un esquema que se repite en todas las novelas de la familia cervantina, y desde luego en Madame Bovary, cuyo personaje central ha sido descrito más de una vez como un Quijote con faldas. No es raro que Miguel de Unamuno, ensayista y poeta, pero hombre más bien ajeno al desarrollo de la novela moderna, notoriamente incómodo en el género, descarte esta vertiente esencialmente literaria del texto de Cervantes. Por eso despacha el capítulo VI del primer Quijote, el del "donoso y grande escrutinio" de los libros, de una plumada, como si fuera un error o una debilidad más del novelista, ya que "trata de libros y no de vida". Pero la autoconfesión de Cervantes en el Quijote y en casi toda su obra, escritor que leía hasta los papeles que encontraba tirados en las calles, según cuenta él mismo, no podía excluir sus opiniones sobre literatura: la vida de los libros estaba en el origen de toda su aventura humana, como le sucede a su personaje, como también le sucedía, por ejemplo, al Licenciado Vidriera. Esta visión de Cervantes desde la literatura, como escritor confeso, deliberado, libresco, permite establecer una relación de lo cervantino con algunos de los escritores más originales, experimentales en el mejor sentido, de la literatura nuestra. Si Cervantes, mal que le pese a su exegeta Unamuno, es un escritor abierta y desenfadadamente libresco, que hace continuas bromas acerca del carácter libresco de su propia obra, que convierte a su propio libro en personaje del libro, como se demuestra a la vuelta de muchas páginas en el Quijote de 1615, donde termina por sustituir a todos los narradores anteriores con la pluma que escribió la novela, también 
podemos enfocar el caso único de Cervantes desde la perspectiva de algunos latinoamericanos atípicos, narradores reflexivos, bromistas, autorreferentes, esencialmente apegados a la letra impresa. Aunque hay otros, quizá muchos otros, me voy a detener un instante en dos casos notables, extremos, sin ninguna intención de hacer un estudio magistral de literatura comparada, sólo como sugerencia o juego literario. Me refiero al brasileño de la segunda mitad del siglo XIX Joaquim Maria Machado de Assis, quien escribía, según su propia confesión, con la pluma de la broma y la tinta de la melancolía, y a Jorge Luis Borges, que tenía tendencia, como todos o casi todos saben, a mirar el mundo bajo la forma de una biblioteca. No puedo comentar aquí el constante uso lúdico que hace Machado de Assis del Quijote, incluso en su forma física de libro, ya que en Quincas Borba coloca de repente una edición en una repisa, encima de un aparador, como testigo mudo de las acciones secretas de una pareja clandestina. En lecturas anteriores, estas apariciones parciales del Quijote en las novelas del Machado de Assis de la madurez me sorprendieron y me dejaron siempre pensativo. Ahora tendría que releer al autor de Memorias póstumas de Brás Cubas, que debió de conocer el Quijote por la intermediación de los "humoristas ingleses" del siglo XVIII, sus escritores favoritos, bajo ese prisma y con ese programa. Es una tarea a la que quizá los invite más adelante. Me voy a permitir ahora, en cambio, un pequeño ejercicio literario a costa de un texto de Borges, libertad que él, quizá, me habría perdonado. Dentro de su gratuidad, el ejercicio en cuestión tiene una virtud: nos permite sospechar que la identidad cervantina, plasmada en una lengua lejana, arcaica, donde la distancia temporal resulta potenciada por la distancia geográfica, es, con todo, a pesar de todo, parte de la identidad nuestra, una referencia y un marco perfectamente vigentes. Toda la obra de Cervantes, y en especial el Quijote, está llena, como ya dije, de lectores, escritores y variados escribidores. Son literatos extravagantes, suavemente obsesivos, agobiados por fijaciones mentales y propósitos absurdos, y tendemos a suponer que todo esto encierra una crítica del quehacer literario como tal, una autocrítica irónica, una forma de desengaño, salvo que se trate de una exaltación de la auténtica creación literaria por contraste con la mala literatura. El escritor confesional, el autor de autobiografías parciales, llámese Gustave Flaubert, Henry James, Marcel Proust, tiende y siempre ha tendido, como ya dije, a poblar sus textos de ficción con otros escritores. Son representaciones sesgadas, bromas, autorretratos burlescos. Yo diría que Laurence Sterne, Marcel Proust, James Joyce, Italo Svevo, Italo Calvino y un largo etcétera, y 
entre nosotros, en forma eminente, Machado de Assis y Borges, pertenecen a esta familia literaria. Sus obras son sistemas de espejos deliberadamente deformados y donde la deformación sirve para acentuar la fuerza de la metáfora. Si se quiere, la del retrato tramposo, incompleto. Son definiciones de sí mismo que proceden por el método de reducción al absurdo. Cervantes es Don Quijote en alguna de sus actitudes vitales, pero sobre todo en el gran hecho de la lectura, que le ha derretido el seso no menos a él que a su personaje. Y la sugerencia de que la vocación literaria, el destino del escritor, tiene en su origen una locura de lector, no anda lejos. Pues bien, algo muy parecido se puede sostener a partir de los curiosos lectores-escritores de Jorge Luis Borges. Uno de ellos, precisamente Pierre Menard, escribe de nuevo el Quijote en el extremo de un proceso de lectura febril, delirante, y no es casual que un personaje lector, inventado a su vez por un lector escritor, repita la historia de otro personaje trastornado por el acto de leer. La relación de Pierre Menard con el Quijote y su creador, y con Don Quijote y su antípoda, Sancho Panza, es obvia. Pero si se lee el episodio de la Cueva de Montesinos, en los capítulos XXII y XXIII del segundo Quijote, y si se lo lee, sobre todo, después de una relectura atenta de El Aleph, uno de los cuentos mayores de Borges, las coincidencias, los juegos de espejo, los parentescos mentales resultan sorprendentes.

El personaje que se ofrece, después del episodio de las bodas de Camacho, para guiar al caballero y a su escudero hasta la cueva de Montesinos, lugar legendario, objeto de rumores contradictorios en la región, recinto oscuro y mágico, el primo del licenciado pueblerino que habíamos conocido en las frustradas y después cambiadas y felices bodas, es uno de los tantos escribidores disparatados de la literatura cervantina. Pertenece y antecede con la mayor propiedad a la estirpe intelectual de un Pierre Menard o de un Carlos Argentino Daneri, el dueño de la casa misteriosa de $E l$ Aleph. Antes de ponerse a escribir el Quijote de nuevo, el inefable Menard ha producido numerosos textos literarios ociosos, enumerados por el narrador en su tono semiserio. Por su lado, Carlos Argentino se ha propuesto "versificar toda la redondez del planeta". Cuando lo encontramos, en el año 1941, ya ha despachado algunas hectáreas del estado de Queensland, un gasómetro cercano a Veracruz, un establecimiento de baños turcos del sur de Inglaterra, junto a otros lugares no menos heterogéneos. Parece que la tendencia enumerativa y la radical y burlesca inutilidad de las enumeraciones son propias de los escritores de la familia cervantina y borgeana. La coincidencia demuestra el significado decisivo del humor en esas escrituras. 
En el capítulo XXII de la segunda parte nos enteramos de que el primo, el que sirve de guía al Caballero de la Triste Figura, se define a sí mismo como humanista de profesión, hombre dedicado a "componer libros para dar a la estampa". Enumera con fruición, con poco disimulado orgullo, sus obras, y ellas contienen a la vez copiosas enumeraciones. Uno de estos libros suyos lleva por título El de las Libreas, y describe setecientas tres libreas "con sus colores, motes y cifras". El otro es una paráfrasis de Ovidio, y el extravagante primo y guía se propone darle el nombre de Metamorfóseos. El tercero de los libros de su pluma es un Suplemento a Virgilio Polidoro. Cuenta que ahí se propuso explicar quién fue el primero que tuvo catarro en el mundo y quién tomó "las primeras unciones para curarse del morbo gálico". Esto del morbo gálico suena a enfermedad venérea, y un historiador de la medicina que asistía a un Congreso de la Lengua me confirmó que se trataba de la sífilis. Don Quijote escucha todo esto con la mayor seriedad, con santa paciencia, lo cual nos confirma que se trata de otro loco, y Sancho, en cambio, encarnación de la sensatez burlona, se dedica a tomarle el pelo al primo y especula sobre quién sería el primer hombre que se rascó en la cabeza. Este Sancho de aquí, como el del final del vuelo de Clavileño, está muy lejos de ser un simplón. Representa, por el contrario, una forma de sabiduría que no se manifiesta con gravedad, que no se toma en serio, que opera a través del humor de raíz popular, con una sensatez gruesa y sólida. En buenas cuentas, concluye Sancho, si Adán tuvo cabeza y cabellos, debe de haber sido el primero en rascarse, así como Lucifer, que fue expulsado del cielo y cayó dando vueltas hasta los abismos, debe de haber sido el primero en voltearse.

El primo pertenece a la categoría muy difundida del escritor mediocre y vanidoso, como Carlos Argentino, perseguidor y gestor de pequeñas glorias literarias. Y Borges, el de la maravillosa interpelación a Beatriz Elena Viterbo, el de "soy yo, soy Borges", vale decir, el Borges personaje de Borges, esta invención autobiográfica y a la vez plenamente ficticia, este otro escritor dentro de la escritura, desempeña, como se verá, un papel equidistante entre Cervantes y su caballero. ¿Por qué? Porque baja, como el caballero, no a una cueva oscura, pero sí al sótano del caserón viejo de la calle Garay de Buenos Aires, y porque ve, ahí, después de haber experimentado cierto malestar, después de haber bebido un coñac de mala clase, situación comparable a la del caballero golpeado por los cuervos y los grajos que salieron volando de la cueva, una parte del universo, parte que es representación del universo entero y a la vez cosa mental, espacio metafí- 
sico, abstracto, ajeno al principio de identidad y al de contradicción. "Vi el populoso mar, vi el alba y la tarde, vi las muchedumbres de América, vi una plateada telaraña en el centro de una negra pirámide, vi un laberinto roto (era Londres), vi interminables ojos inmediatos escrutándose en mí como en un espejo..."

Por su belleza, por su magia, por su vuelo poético, la visión es digna del Borges inventado por Borges, del Borges como metáfora. Así como la visión de don Quijote en la oscuridad de la cueva de Montesinos es digna del Cervantes que se proyectaba en el Caballero de la Triste Figura, que se contaba a sí mismo, a la manera de Montaigne, y que al hacerlo se inventaba. Es, en buenas cuentas, en el texto del siglo XVII, una exaltada enumeración de elementos que salen de la profundidad, de la fantasía de la Edad Media, fantasía ingenua, infantil, y a la vez abigarrada, astuta, cargada de sabiduría, y en el del siglo XX, en ese improbable sótano de la calle Garay, una lista de aspectos simultáneos del universo, fragmentos llenos de imposibilidad: visiones metafísicas convertidas, precisamente, en ramas de la literatura fantástica. Retroceden en ambos episodios, en el de la cueva y el del Aleph, silenciados, descartados del primer plano, el escribidor de las libreas y el de las hectáreas, los gasógenos, los establecimientos de baños turcos. Las enumeraciones inferiores, absurdas, dan ahora lugar a letanías poéticas: al gran misterio universal ("vi tigres, émbolos, bisontes, marejadas y ejércitos, vi todas las hormigas que hay en la tierra, vi un astrolabio persa ...”). Estábamos en los terrenos de una literatura inferior, de caricatura, y hemos pasado a estadios superiores, a cumbres, ni más ni menos, de la lengua. El caballero, sentado en la profundidad, se queda dormido y al cabo de un rato despierta. Lo que nos transmite es la versión suya, sin testigos posibles, pero nos pide, nos insta a que le creamos. Se abren grandes puertas de un palacio transparente y un venerable anciano de luengas barbas, Montesinos, avanza y le dice a don Quijote de la Mancha que lo estaban esperando hacía muchos años. Esa larga espera ya nos coloca en un tiempo soñado, un tiempo de ficción pura. La visión quijotesca es nostálgica, propia de un presente inferior al pasado, sentimiento que domina con sutileza, con ironía, entre líneas, en la totalidad del libro. Para mí, en esta culminación de la segunda parte, el Quijote ya es un libro de nostalgia, de inadaptación. La contemplación extasiada de la Edad Media en sus expresiones más irreales, en su mitología, entra en inevitable conflicto con el presente. Guadiana es un escudero convertido en río, que cada cierto trecho se hunde debajo de la tierra y que después reaparece. Todos han sido encantados por el 
viejo mago Merlín, antecesor de Montesinos, y don Quijote, por el solo hecho de bajar a esos recintos, participa del encantamiento. En una sala del palacio transparente, sobre un sepulcro, hay un caballero muerto, Durandarte, pero su cuerpo, a pesar de los años que han transcurrido, ese tiempo indefinido, paralizado, no es de mármol, de jaspe o bronce, "como los suele haber en otros sepulcros", sino de carne y hueso. La dueña Ruidera y sus hijas y sobrinas han sido convertidas en otras tantas lagunas colocadas en la región de la Mancha, en las cercanías del lugar no completamente preciso de donde venía el otro caballero, es decir, el personaje nuestro, el de la Triste Figura. Después sabemos que Montesinos, en cumplimiento de la última voluntad de Durandarte, le había sacado el corazón y se lo había entregado a Belerma, la señora de sus pensamientos, que no era inferior, a pesar de lo que le costaba admitirlo a don Quijote, a Dulcinea del Toboso. Poco más adelante vemos desfilar a Belerma, vestida de negro, con tocas blancas que llegan hasta la tierra, llevando un lienzo con el corazón momificado de Durandarte. Estamos acostumbrados, por algún motivo, a ver la literatura en lengua española como literatura del realismo, de la picaresca, de la vida popular en sus expresiones más elementales, por lo menos la literatura anterior, digamos, a Pedro Páramo o a Cien años de soledad, y ocurre, sin embargo, que las páginas de más extremada y exaltada fantasía de toda la narrativa europea se escribieron en la España de comienzos del siglo XVII, la del primer barroco. Y el autor moderno más emparentado con esta fantasía cervantina, que hizo de puente entre la Edad Media y la era del Barroco, no es uno de los cultivadores reconocidos del realismo mágico, no son las figuras consabidas de un Alejo Carpentier o un Gabriel García Márquez, sino, y en forma paradójica, ya que su mundo imaginario, por lo menos a primera vista, tiene orígenes más cosmopolitas, más intelectuales, incluso más librescos, Jorge Luis Borges.

La enumeración mágica del episodio de la cueva de Montesinos, narrada en los capítulos XXII, XXIII y XXIV del segundo Quijote, tiene un contexto histórico y literario preciso. Es una fantasía desatada, pero deriva de una literatura concreta, que se entrelaza con el humor cervantino y que éste, a su vez, recrea, reescribe. Y es, por lo demás, una fantasía conectada con otra de las claves imaginarias de la segunda parte: el episodio del vuelo del caballo de palo Clavileño en la mansión de los duques, contado en el capítulo XLI. Aquí Sancho Panza, con fruición, con regocijo, describe lo que vio en los diferentes niveles del cielo durante su vuelo inmóvil. Es una perfecta tomadura de pelo, una demostración clara de que el Sancho de 
Vladimir Nabokov, ese "payaso generalizado", fue lamentablemente mal entendido. Y al final del episodio se produce uno de los intercambios más sorprendentes de toda la obra. Don Quijote se acerca a Sancho y le dice al oído: "Sancho, pues vos queréis que se os crea lo que habéis visto en el cielo, yo quiero que vos me creáis a mí lo que vi en la cueva de Montesinos. Y no os digo más".

Es decir, don Quijote propone un pacto de credibilidad, y es, quizá, el pacto implícito, en definitiva, en toda obra de ficción: el pacto de Cervantes y de todos sus seguidores. Después de la fantástica enumeración de lo que contempló en el Aleph, desfile no sólo de la Edad Media sino del universo entero, desfile que no era ni podía ser desfile, puesto que era simultáneo, el Borges del relato, el otro Borges, enfoca el problema central de la ficción de una manera parecida. En la culminación del cuento, en su "inefable centro", empieza, confiesa la voz narrativa, "mi desesperación de escritor". Pero al final, después de contarle al lector todo lo que ha visto, concibe una venganza que es la más literaria de las venganzas. Don Quijote le propone a Sancho un pacto de credibilidad. Se lo puede proponer porque Sancho es un alter ego, otra voz, otra entelequia, pero la proyección de una misma persona. Borges, en cambio, esto es, el otro Borges, le da un abrazo a Carlos Argentino Daneri, le agradece su hospitalidad, le da un par de consejos razonables y se va de la casa sin contarle nada, poniendo así en duda y en solfa todos los supuestos del otro. Si la historia no se cuenta, no existe, o sólo existe para nosotros, y no para el absurdo Carlos Argentino. En otras palabras, Borges, el Borges de la ficción, no toma en serio a Carlos Argentino. Don Quijote, en cambio, conoce la sabiduría final de Sancho Panza y la respeta.

Hablé de la frase de Machado de Assis, el brasileño: escribir con " $a$ pena da galhofa e a tinta da melancolia", la pluma de la broma y la tinta de la melancolía. Es toda una declaración de principios: un signo y un síntoma. La pluma de Cervantes y la de Borges, como la de Machado de Assis, como la del inglés Sterne, como la de algunos otros, son similares, parientes cercanas, y están empapadas en la misma tinta. Recurro, sin embargo, a mi texto de las Memorias póstumas de Brás Cubas (Instituto Nacional del Libro, Río de Janeiro, 1960), y me encuentro con un detalle esencial y que se me había olvidado: la frase no forma parte del prólogo del autor sino de la advertencia al lector escrita por Brás Cubas, el personaje. En buenas cuentas, habla un escritor o escribidor tan ficticio como el de las libreas, como Pierre Menard, como Carlos Argentino, y, para colmo, difunto. Es, entonces, 
otra vuelta de tuerca, una broma literaria al cuadrado. Podemos cerrar el texto con esta broma, e implorando el perdón de dos sectores peligrosos de la literatura: el de las academias y el de los críticos dinamiteros. 